\title{
Neurofibromatosis type 2 (NF2): A clinical and molecular review
} D Gareth R Evans

Address: Medical Genetics Research Group, Regional Genetics Service and National Molecular Genetics Reference Laboratory, Central Manchester Foundation Trust, St Mary's Hospital, Manchester M13 0JH, UK

Email: D Gareth R Evans - dgr.evans@virgin.net

Published: 19 June 2009

Orphanet Journal of Rare Diseases 2009, 4:16 doi:10.1 I86/I750-I I72-4-16

This article is available from: http://www.ojrd.com/content/4/I/16

(c) 2009 Evans; licensee BioMed Central Ltd.

This is an Open Access article distributed under the terms of the Creative Commons Attribution License (http://creativecommons.org/licenses/by/2.0), which permits unrestricted use, distribution, and reproduction in any medium, provided the original work is properly cited.

\begin{abstract}
Neurofibromatosis type 2 (NF2) is a tumour-prone disorder characterised by the development of multiple schwannomas and meningiomas. Prevalence (initially estimated at I: 200,000) is around I in 60,000. Affected individuals inevitably develop schwannomas, typically affecting both vestibular nerves and leading to hearing loss and deafness. The majority of patients present with hearing loss, which is usually unilateral at onset and may be accompanied or preceded by tinnitus. Vestibular schwannomas may also cause dizziness or imbalance as a first symptom. Nausea, vomiting or true vertigo are rare symptoms, except in late-stage disease. The other main tumours are schwannomas of the other cranial, spinal and peripheral nerves; meningiomas both intracranial (including optic nerve meningiomas) and intraspinal, and some low-grade central nervous system malignancies (ependymomas). Ophthalmic features are also prominent and include reduced visual acuity and cataract. About $70 \%$ of NF2 patients have skin tumours (intracutaneous plaque-like lesions or more deep-seated subcutaneous nodular tumours). Neurofibromatosis type 2 is a dominantly inherited tumour predisposition syndrome caused by mutations in the NF2 gene on chromosome 22. More than $50 \%$ of patients represent new mutations and as many as one-third are mosaic for the underlying disease-causing mutation. Although truncating mutations (nonsense and frameshifts) are the most frequent germline event and cause the most severe disease, single and multiple exon deletions are common. A strategy for detection of the latter is vital for a sensitive analysis. Diagnosis is based on clinical and neuroimaging studies. Presymptomatic genetic testing is an integral part of the management of NF2 families. Prenatal diagnosis and pre-implantation genetic diagnosis is possible. The main differential diagnosis of NF2 is schwannomatosis. NF2 represents a difficult management problem with most patients facing substantial morbidity and reduced life expectancy. Surgery remains the focus of current management although watchful waiting with careful surveillance and occasionally radiation treatment have a role. Prognosis is adversely affected by early age at onset, a higher number of meningiomas and having a truncating mutation. In the future, the development of tailored drug therapies aimed at the genetic level are likely to provide huge improvements for this devastating condition.
\end{abstract}

\section{Disease name and synonyms}

Neurofibromatosis type 2(NF2), Bilateral acoustic neurofibromatosis, Central neurofibromatosis. OMIM \#101000

\section{Definition}

Neurofibromatosis type 2 (NF2) is a dominantly inherited tumour prone disorder characterised by the development of multiple schwannomas and meninigiomas [1]. 
The disease can be diagnosed when a pathogenic mutation in the NF2 gene is identified or when the criteria in table 1[1] are fulfilled.

\section{Epidemiology}

When using established clinical diagnostic criteria [1] and based on mutations in the NF2 gene [2,3] assessment of the frequency of NF2 in the population can be made. This is complicated by the high rate of mosaicism [4]. There have only been two epidemiological studies of NF2 one in North West England [5,6], [Evans DG et al. Birth incidence and prevalence of tumour prone syndromes: estimates from a UK genetic family register service. Am J Med Genet 2009. unpublished] and one in Finland [7]. The incidence of NF2 was initially reported as 1:33-40,000 individuals in a 4 million population in England [5]. Disease prevalence was somewhat lower at $1: 200,000$. However, a recent update suggests that the incidence may be as high as $1: 25,000[6]$. Disease prevalence has now risen to around 1 in 60,000 due to earlier diagnosis and better survival due to improved treatment [Evans DG et al. Birth incidence and prevalence of tumour prone syndromes: estimates from a UK genetic family register service. Am J Med Genet 2009. unpublished]. A lower incidence of 1 in 87,410 was reported in a 1.7 million population in Finland [7].

\section{Clinical description}

NF2, in contrast to neurofibromatosis type 1 (NF1) is characterised by the development of schwannomas, meningiomas and ependymomas, with the great majority of patients developing bilateral schwannoma involvement of the superior vestibular branch of the eighth cranial nerve [1]. Although the disease is still classified as "neurofibromatosis", neurofibromas are relatively infrequent. The first clear description of NF2 was in 1822 by Wishart [8]. NF1 was fully delineated in the late nineteenth century by von Recklinghausen. However, it was the eminent Harvey Cushing, who described bilateral eighth nerve tumours occuring as part of von Recklinghausen disease in 1916 [9]. This description is largely responsible for the confusion between the two conditions which continued for many years. Indeed, the literature prior to 1985 has many NF2 cases being described as part of von Reckling- hausen disease, with bilateral vestibular schwannomas (VS) being included in a major patient series [10].

The hallmark of NF2 is the development of bilateral VS. VS usually present with hearing loss, tinnitus or imbalance or a combination of the three symptoms. The other main tumour features are schwannomas of the other cranial, spinal and peripheral nerves; meningiomas both intracranial (including optic nerve meningiomas) and intraspinal; and some low-grade central nervous system (CNS) malignancies (ependymomas and gliomas). Four large clinical studies have now confirmed this clinical picture [1,11-13] (Table 2). Individuals may present with cranial meningiomas or a spinal tumour long before the appearance of a VS.

The majority of individuals with NF2 present with hearing loss, which is usually unilateral at time of onset. The hearing loss may be accompanied or preceded by tinnitus. VS may also cause features such as dizziness or imbalance as the first symptom. Nausea, vomiting or true vertigo are rare symptoms except in late stage disease.

A significant proportion of cases (20-30\%) present with symptoms from an intracranial meningioma (headaches, seizures), spinal tumour (pain, muscle weakness, paraesthesia), or cutaneous tumour [1,11-13]. Indeed, the first sign of more severe multi-tumour disease in early childhood is often a non- $8^{\text {th }}$ nerve tumour (including a cutaneous tumour), or an ocular presentation [14]. Adult presentation is thus quite different to paediatric presentation, in which VS accounts for as little as $15-30 \%$ of initial symptoms. There also appears to be a tendency to mononeuropathy, particularly affecting the facial nerve causing a Bell's-like palsy, which does not fully recover years before the detection of a VS. Some children present with a poliolike illness with wasting of muscle groups in a lower limb, which again does not fully recover. In adulthood, a more generalised symptomtatic severe polyneuropathy occurs in about $3-5 \%$ of patients, often associated with an "onion bulb" appearance on nerve biopsy [1]. This can progress, leading to severe muscle wasting and even death. However, around $40 \%$ of patients will show evidence of polyneuropathy on nerve conduction studies [15].

Table I: Diagnostic criteria for Neurofibromatosis type 2 (these include the NIH criteria with additional criteria)

\begin{tabular}{ll}
\hline Main criteria & Additional criteria \\
\hline Bilateral vestibular schwannomas (VS) or family history of NF2 plus & $\begin{array}{l}\text { Unilateral VS plus any two of: meningioma, glioma, neurofibroma, } \\
\text { schwannoma, and posterior subcapsular opacities } \\
\text { or }\end{array}$ \\
$\begin{array}{ll}\text { I) Unilateral VS or } & \text { Multiple meningioma (two or more) plus unilateral VS or any two of: } \\
\text { 2) Any two of: meningioma, glioma, neurofibroma, schwannoma, } & \text { glioma, neurofibroma, schwannoma, and cataract }\end{array}$ \\
\hline
\end{tabular}


Table 2: Clinical characteristics of Neurofibromatosis type 2 patients in four studies

\begin{tabular}{|c|c|c|c|c|}
\hline Characteristic & Study & & & \\
\hline & Kanter et al. [II] & Evans et al. [I] & Parry et al. [12] & Mautner et al. [13] \\
\hline Number of cases & 73 & 120 & 63 & 48 \\
\hline Number of families & 17 & 75 & 32 & 44 \\
\hline Sporadic cases & 0 & 45 & 17 & 44 \\
\hline Mean age at onset (years) & 20 (of 59) & 22 & 20 & 17 \\
\hline Intracranial meningiomas (\%) & 18 & 45 & 49 & 58 \\
\hline Spinal tumours (\%) & NA & 26 & 67 & 90 \\
\hline Skin tumours (\%) & 32 (of 73 ) & $68($ of 100$)$ & 67 & 64 \\
\hline Café-au-lait macules (\%) & 42 (of 31$)$ & 43 (of 100) & 47 & NA \\
\hline Cataract (\%) & NA & 38 (of 90) & 81 & 62 \\
\hline Intracranial astrocytoma (\%) & NA & 4.1 & 1.6 & NA \\
\hline Ependymoma (\%) & NA & 2.5 & 3.2 & 6 \\
\hline Optic sheath meningioma (\%)! & NA & 4.1 & 4.8 & 8 \\
\hline
\end{tabular}

IIn Mautner et al., the frequency of optic nerve sheath tumours is for all histological types (i.e., schwannomas and meningiomas).

Ophthalmic features are also prominent in NF2. Patients often suffer from reduced visual acuity of various causes. Between $60-80 \%$ of patients have cataracts $[1,10,11]$, which are usually presenile posterior subcapsular lenticular opacities that rarely require removal. However, cortical wedge opacities may be present from near birth. Optic nerve meningiomas can cause visual loss in the first years of life and extensive retinal hamartomas can also affect vision. Misdiagnosis of both of these abnormalities as retinoblastoma has led to the eye being removed in the first few years of life.

The skin is a useful aid to diagnosis, but cutaneous features in NF2 are much more subtle than in NF1. About $70 \%$ of NF2 patients have skin tumours, but only $10 \%$ have more than ten skin tumours. The tumours appear to be of at least three different types. The most frequent type is a plaque-like lesion, which is intra-cutaneous, slightly raised and more pigmented than surrounding skin, often with excess hair. More deep-seated subcutaneous nodular tumours can often be felt, sometimes on major peripheral nerves. These tumours occur as a fusiform swelling of the nerve with thickened nerve palpable on either side. There are also occasional intracutaneous tumours similar to those in NF1. The great majority of these tumours are schwannomas, but occasional definite neurofibromas do occur.

\section{Etiopathogenesis}

NF1 and NF2 were eventually recognised as separate genetic and clinical diseases with the localisation of the respective genes to chromosome 17 and $22[16,17]$. This was followed by the formal clinical delineation at a National Institutes of Health (NIH) consensus meeting in the USA in 1987 [18]. It is now clear that NF2 is a genetically homogeneous condition, with no evidence for another genetic cause of classical NF2 (bilateral VS).

Seizinger $e$ al. were the first to show loss of constitutional heterozygosity of chromosome 22, with DNA markers lost in tumours from a patient with NF2 [19]. As such NF2 was one of the first inherited tumour prone disorders to be localised to a specific genetic location. Linkage studies then confirmed that all affected members of the large family carried the same copy of chromosome 22q. The NF2 gene was then isolated by the simultaneous discovery of constitutional and tumour deletions in a gene coding for a cell membrane-related protein, which has been termed merlin or schwannomin by the two groups who isolated it $[2,3]$. 


\section{Constitutional mutations}

Standard mutation techniques, such as Single Strand Conformational Polymorphism (SSCP) analysis or Denaturing Gradient Gel Electrophoresis, detected between 35\% and $66 \%$ of pathogenic mutations [20-23]. The majority of these mutations were truncating mutations, leading to a smaller and probably non-functional protein product. Early studies suggested that missense mutations (which result in a complete protein product) and large deletions (which result in no protein product) both caused predominantly mild phenotypes. Larger studies of detailed genotype/phenotype correlations in multiple families have confirmed this finding [21-26]. Phenotype is more variable in patients with splice-site mutations, with milder disease in patients with mutations in exons 9-15 [26,27]. Definitive evidence from effects on survival have been established with missense mutation patients having statistically greater survival than nonsense and frameshift mutations [26]. As in other tumour prone disorders the frequency of large genomic rearrangements did not become apparent until some time after the gene was cloned, due to the poor availability of methods to allow routine clinical screening for their presence. About half of these are detectable with standard cytogenetic analysis with FISH [28]. A small number of constitutional abnormalities such as chromosome translocations and ring 22 would still need a cytogenetic analysis to confirm their presence. The majority of large scale rearrangements are now routinely detected by Multiplex Ligation-dependant Probe Amplification (MLPA) and are known to account for around $15 \%$ of NF2 germline aberrations [28,29]. The commonest of this class of mutations is a deletion of the NF2 promoter, exon 1 and most of intron 1 and deletions of the whole gene, indeed combined these two account for over half of all MLPA abnormalities (Table 3). The differing frequency of the various types of NF2 mutation between familial, sporadic and mosaic cases can be seen in Table 4. This represents the output from one centre dedicated to whole gene analysis with the great majority of patients having been screened by a technique capable of the detection of large deletions or duplications. More extensive lists of NF2 mutations described worldwide are available online and in recent reviews [30-32], but these are less likely to reflect the true ratios of different classes of mutations, as a variety of different techniques have been used. The sensitivity of genetic testing using sequence analysis and MLPA can be derived from column 1 (Table 1). Ninety-three per cent of mutations have been identified in the second generation of NF2 families. Of the missing eight families six have been subjected to more detailed analysis including RNA analysis. Two putative splicing variants deep in the introns have been identified based on Protein Truncation Testing and intronic sequencing (Messaien $\mathrm{L}$, personal communication), but no other mutations have been found.
A considerable proportion of NF2 patients, particularly milder cases, have mosaic disease, in which only a proportion of cells contain the mutated NF2 gene. The initiating mutation occurs after conception, leading to two separate cell lineages. The proportion of cells affected depends on how early in development the mutation occurs. Recent evidence suggests that up to $20-30 \%$ of NF2 cases without a family history of the disease are mosaic, carrying the mutation in too small a proportion or none of their lymphocytes to be detected from a blood sample [4,33-35]. This accounts for the milder disease course in many individuals with unfound mutations, and since only a subset of germ cells (or none) will carry the mutation, there is less than a $50 \%$ risk of transmitting the disease to their offspring. However, if an offspring has inherited the mutation, they will have a typical phenotype and usually be more severely affected than their parent, since the offspring will carry the mutation in all of their cells. One of the features that suggested that mosaicism existed in NF2 was that NF2 mutations were harder to find in blood in isolated non inherited cases than in patients who had inherited the disease from an affected parent. Mosaicism may be particularly likely in NF2 if the tumours are predominantly on one side of the body. The mosaic mutation can be detected by analysing tumour material from an affected individual. If an identical mutation is found in two tumours from that individual, their offspring can be tested for the presence of the mutation. Also when two alterations, either: two mutations or one mutation plus one allele loss, are found in on tumour, one of these must be the constitutional one. Thus offspring can be tested for both abnormalities and potentially exclude inheriting NF2.

$\mathrm{C}>\mathrm{T}$ transitions leading to a nonsense mutation are the most common mutations in the NF2 gene [30-32]. These account for the only significant variation in mutation frequency across the NF2 gene apart from the lack of mutations in exons 16 and 17 and a relatively low frequency in exon 9 [30].

\section{Somatic mutations}

There are notable similarities, but also differences between the distribution and type of germline and somatic NF2 mutations. Among germline mutations in classic NF2, nonsense mutations are more common than frameshift mutations by a ratio of $1.3: 1$, but this ratio is reversed for somatic mutations [36]. In both situations NF2 nonsense mutations, $\mathrm{C}>\mathrm{T}$ transitions in CGA codons and non-CGA codons are the most common single base-pair transitions. However there is a marked absence of mutations in exons 14 and 15 in sporadic meningioma. One recently reported phenomenon is the increasing drift from nonsense mutations in the germline and early somatic mutations to a predominance of 
Table 3: MLPA abnormalities in 62 unrelated families

\begin{tabular}{|c|c|}
\hline MLPA abnormality & Number of occasions (mosaic) \\
\hline Exon I-intron I (deletes intronic CA repeat) & $18(3)$ \\
\hline Whole gene (exons I-17) deletion & $16(2)$ \\
\hline Exons 5-17 deletion & $3(2)$ \\
\hline Exons $2-3$ deletion & 2 \\
\hline Exons $2-10$ deletion & 2 \\
\hline Exons $13-15$ deletion & 1 \\
\hline Exons $\mathrm{I}-16$ deletion & $2(1)$ \\
\hline Exons $1-10$ deletion & $3(1)$ \\
\hline Exons $\mathrm{I}-3$ deletion & I \\
\hline Exons $\mathrm{I}-4$ deletion & $2(1)$ \\
\hline Exons $\mathrm{I}-2$ deletion & $I(I)$ \\
\hline Exons $15-17$ deletion & 1 \\
\hline Exons 8-17 deletion & 1 \\
\hline Exons 8-15 deletion & I \\
\hline Exon 3 deletion & I \\
\hline Exon 7 deletion & 1 \\
\hline Exon 5 deletion & 1 \\
\hline Exons $12-14$ duplication & 1 \\
\hline Exons $10-16$ duplication & 1 \\
\hline Exon 2 deletion & I \\
\hline Exon 8 deletion & 1 \\
\hline Exons $2-4$ deletion & I \\
\hline
\end{tabular}

MLPA- Multiplex Ligation-dependant Probe Amplification

frameshift mutations in the tumours of older patients with vestibular schwannoma [36]. This is likely to be due to a deficiency in certain DNA repair pathways in older patients [36].

Although it is thought that effectively all schwannomas require inactivation of the NF2 gene, no reports apart from those studying NF2 protein have confirmed a 100\% knock out of both copies of the NF2 gene. This is likely to be due to diversity of mechanisms that inactivate the gene. The standard approach of mutational analysis and Loss of Constitutional Heterozygosity (LOH) on tumours will detect involvement of NF2 in about $80-90 \%$ of schwannomas, but both copies can only be confirmed as affected in about $50-60 \%$ of cases. The mechanism of LOH is also not straightforward, whilst most cases involve loss of 
Table 4: Mutations identified in 529 families with Neurofibromatosis type $\mathbf{2}$ in the Manchester (UK) genetics laboratory

\begin{tabular}{|c|c|c|c|c|}
\hline Type of mutation & $\begin{array}{l}\text { Detection in } 2^{\text {nd }} \text { generation } \\
(n=108)\end{array}$ & $\begin{array}{l}\text { Detection in sporadic non mosaic } \\
\text { patients (\% non mosaic) }\end{array}$ & Mosaic mutations (\% of mosaic) & Total \\
\hline Splice site & $35(32 \%)$ & $43(22 \%)$ & $3(4 \%)$ & $80(15 \%)$ \\
\hline MLPA positive & $23(20 \%)$ & $28(14 \%)$ & II (I5\%) & $62(12 \%)$ \\
\hline FSD & $18(17 \%)$ & $36(18 \%)$ & $20(26 \%)$ & $74(13 \%)$ \\
\hline Nonsense & $16(15 \%)$ & $67(35 \%)$ & $28(37 \%)$ & III (22\%) \\
\hline Missense & $7(6 \%)$ & $5(3 \%)$ & I (1\%) & $13(2.5 \%)$ \\
\hline FSI & $3(3 \%)$ & II (7\%) & $6(8 \%)$ & $20(4 \%)$ \\
\hline IFD & I (I\%) & I & $3(4 \%)$ & $5(1 \%)$ \\
\hline Ring 22 & 0 & 0 & $3(4 \%)$ & 3 \\
\hline Not found & $7(7 \%)$ & $230(55 \%)$ & 158 & $166 / 529(31 \%)$ \\
\hline Total & 108 & $191 / 421$ (45\%) & 72 & 529 \\
\hline
\end{tabular}

chromosome 22 or at least the long arm, a proportion are now known to be due to mitotic recombination with essentially two identical copies of a mutated NF2 gene and distal 22q [37]. This mechanism is now thought to be a primary cause of NF2 inactivation in schwannomatosis. It is now known that between $20-40 \%$ of sporadic schwannomas are inactivated by NF2 methylation $[38,39]$ and in a similar fashion to TP16 this could involve both copies of NF2 and explain why some tumours do not harbour identifiable point mutations or LOH. Approximately $60 \%$ of sporadic meningiomas have NF2 gene involvement and promoter methylation again plays a significant role [40].

\section{Diagnosis}

The Manchester (modified NIH) diagnostic criteria for NF2 are shown in Table 1. The original NIH criteria have been expanded to include patients with no family history who have multiple schwannomas and or meningiomas, but who have not yet developed bilateral $8^{\text {th }}$ nerve tumours. Patients who have asymmetric involvement are likely to be mosaic [41]. At very young ages (< 18 years) individuals presenting with an apparently isolated meningioma [14] or vestibular schwannoma [42] are have a $20 \%$ and $10 \%$ likelihood respectively of developing NF2. However after 20 years of age this rate drops dramatically and the diagnosis becomes very unlikely after 30 years of age [42].

\section{Diagnostic methods}

- Clinical and family history
- Examination including cutaneous and ophthalmic (Slit lamp)

- Craniospinal MRI

- Molecular analysis

\section{Differential diagnosis}

The main differential diagnosis of NF2 is schwannomatosis and some patients with multiple non cranial schwannomas turn out to have mosaic NF2 [34,35]. However, patients fulfilling the most sensitive Manchester criteria are unlikely to be misclassified [43].

\section{Antenatal diagnosis and genetic counselling}

NF2 is an autosomal dominant disease with usually a $50 \%$ risk of transmission from an affected individual to their offspring. This was first confirmed in a large family reported by Gardner and Frazier in 1930. 50-60\% of patients have no family history and represent de novo mutations in the NF2 gene [1-3]. Individuals who inherit a pathogenic mutation in the NF2 gene will almost always develop symptoms by 60 years of age [7]. Exceptionally, patients particularly in the pre MRI era will have not been diagnosed in their lifetime. Although the transmission rate is $50 \%$ in the second generation and beyond, the risk of transmission in an apparently isolated patient with NF2 is less than $50 \%$ due to mosaicism [4].

Because detection of tumours at an early stage is effective in improving the clinical management of NF2, pre-symp- 
tomatic genetic testing is an integral part of the management of NF2 families. Once a mutation has been identified in an affected individual, a $100 \%$ specific test is available for the family. However, mutation screening may not reveal the causative mutation. Predictive diagnosis by linkage analysis using intragenic markers or markers flanking the NF2 gene is also possible in the great majority of families with two or more living affected individuals. In the absence of a genetic test a cumulative age at onset curve [44] can be used. Age at onset curves aid genetic counselling; for example, the risk of having inherited NF2 for an asymptomatic at-risk individual 25 years of age, prior to screening, drops to $25 \%$. The risk to an unaffected 30 year old with a normal scan would be $<10 \%$. Tumour analysis plays a vital role in providing genetic testing for the offspring of sporadic patients. Indeed analysis should if possible first be carried out on tumour so that a targeted approach can be used on the blood sample. If both mutational events are identified in the NF2 gene in a tumour and neither is present in the blood the patient must be mosaic for one of these mutations [33-35,45,46]. Even if only LOH is identified this still allows exclusion of NF2 in $50 \%$ of offspring if they can be shown to have inherited the allele "lost" in the tumour $[35,46]$. At-risk individuals who are shown not to have inherited the mutated NF2 gene do not need further follow-up.

Even in the absence of identifying a mutation the residual risk of NF2 can be substantially reduced in the child of an apparently isolated case. In particular patients presenting with asymmetric disease over 40 years of age with negative mutation analysis in blood would have a very low chance of transmitting NF2 to their children (Table 5).

Because of the severity of NF2 there is a demand for prenatal diagnosis and pre-implantation genetic diagnosis. Use of the techniques above means that this is possible in the great majority of families.

\section{Screening protocol}

Children of affected patients should be considered to be at 50\% risk of NF2 and screening for NF2 can start at birth. Cataracts can affect vision in early life and other tumour implications are present in the first ten years of life, particularly cranial meningiomas. Formal screening for VS should start at ten years, as it is rare for tumours to become symptomatic before that time even in severely affected families. Annual audiological tests including auditory brainstem response are still a useful adjunct to MRI [44]. Surgery is unlikely to be more successful for tumours $<6 \mathrm{~mm}$ than for tumours sized $6 \mathrm{~mm}$, but VS growth is higher in younger patients, so for asymptomatic at-risk individuals without tumours, MRI screening every two years for those $<20$ years old and every 3-5 years for those age $>20$ years should be sufficient. The initial MRI scan could be at around 12 years of age, or 10 years in severely affected families. Once tumours are present, MRI screening should probably be at least annual. Spinal tumours are seen in $60-80 \%$ of NF2 patients on MRI [47$50]$. While only $25-30 \%$ of patients with spinal tumours require a spinal operation from a symptomatic tumour, a full annual neurological examination is probably a wise precaution with Spinal MRI only every 3 years or if there

Table 5: Transmission risks to offspring for isolated cases of Neurofibromatosis type 2 before and after negative mutation testing.

\begin{tabular}{llllll}
\hline & Number & PRE testing Mosaic inferred & $\begin{array}{l}\text { PRE testing Transmission } \\
\text { risk }\end{array}$ & $\begin{array}{l}\text { POST genetic negative } \\
\text { testing in blood Mosaic } \\
\text { inferred }\end{array}$ & $\begin{array}{l}\text { POST genetic negative testing } \\
\text { in blood Transmission risk }\end{array}$ \\
\hline$<20$ BVS & 85 & $12 \%$ & $45 \%$ & $46 \%$ & $30 \% 1$ in 3 \\
\hline$<20$ UVS & 21 & $42 \%$ & $33 \%$ & $87 \%$ & $11 \% 1$ in 9 \\
\hline $20-29$ BVS & 67 & $27 \%$ & $36 \%$ & $78 \%$ & $16 \% 1$ in 6 \\
\hline $20-29$ UVS & 27 & $78 \%$ & $19 \%$ & $97 \%$ in 12 \\
\hline $30-39$ BVS & 54 & $50 \%$ & $28 \%$ & $88 \%$ & $11 \% 1$ in 9 \\
\hline $30-39$ UVS & 19 & $85 \%$ & $12 \%$ & $98 \%$ & $6 \% 1$ in 16 \\
\hline $40+$ BVS & 53 & $63 \%$ & $22 \%$ & $93 \%$ & $9 \% 1$ in 11
\end{tabular}

Results are based of outcomes of testing in first affected family members and on age at onset and laterality of presentation with vestibular schwannomas (VS).

BVS - presentation with bilateral VS; UVS - initial presentation with unilateral VS 
are new symptoms. If no tumours are present on the initial scan a further scan 5-10 years later may be reasonable.

In most families it is now possible to develop a genetic test so that screening can be targeted to affected individuals only. Identifying the affected patient's mutation not only allows testing of at risk relatives, but may also give important indicators as to the patient's own prognosis. As 25$30 \%$ of NF2 patients are mosaic frozen tumour should be taken at operation (with patient consent) for genetic tests.

\section{NF2 management}

NF2 presents many difficult management dilemmas. The mainstay of management of NF2 is surgical removal of symptomatic cranial and spinal tumours. The timing of removal of vestibular schwannomas is a more difficult area. Surgical results are certainly far better when managed by an experienced team [50-52]. There is clear evidence of a reduction in mortality with a significantly increased life expectancy for NF2 patients managed at 3 specialty centres in the UK (OR 0.34) [53]. It is important to balance the use of microsurgery and radiation treatment, which can have a role in patients who have particularly aggressive tumours, or who are poor surgical risks, or who refuse surgery. Teams experienced in the positioning of brainstem implants can offer partial auditory rehabilitation to those who are deaf, although results are still behind those achievable for cochlear implants. Although the cochlear nerve may be left initially intact after surgery its blood supply may be damaged, nonetheless a few patients can be rehabilitated successfully with a cochlear implant.

\section{Outcomes}

Even with improvements in microsurgery and with use of radiation therapy, the great majority of individuals with NF2 become completely deaf. The tumours in NF2 are more difficult to treat than those of sporadic unilateral VS, as NF2 VS are often multifocal, appearing "like a bunch of grapes" around the vestibular nerve in particular. There is evidence for a histological difference, with NF2 VS being more lobular and less vascular then their sporadic counterparts [54]. This leads to a greater risk of facial nerve damage in NF2. Loss of facial nerve function is one of the most feared aspects of the condition for many sufferers, although in good surgical hands this complication is now much less common [50,52]. Patients may also be severely disabled by a combination of poor balance, visual problems and weakness due to spinal tumours. Indeed, many NF2 patients become wheelchair-bound in early adulthood. Many patients with multi-tumour disease die in their twenties and thirties. In view of the multiplicity of problems affecting many patients it is strongly recommended that NF2 patients are managed by a multidisciplinary team in specialist centres [52].

\section{Specialty centres}

A typical NF2 specialist centre will require involvement of a number of key staff members.

\section{Permanent clinic staff}

Neurosurgeon, Otolaryngologist, physician (neurologist/ geneticist), clinic nurse/patient link worker and a dedicated clinic secretary.

Clinic equipment: lightwriter/pallantype/voice activated software.

In order to minimise patient visits morning scanning with lunchtime radiological review and an afternoon clinic is preferable.

\section{Each clinic should have access to a named}

Neuroradiologist, ophthalmologist, peripheral nerve surgeon, plastic surgeon, neurologist/geneticist (if not involved in main clinic), hearing therapist, physiotherapist, paediatrician.

Patients should be given the option of a radiation therapy opinion, which will only be available at a few centres.

\section{Managing affected children}

NF2 is being recognised more and more frequently in childhood often before VS have developed. Recognition of the more severe disease course with early presentation and the more atypical features such as mononeuropathy are important.

\section{Surgery}

VS in NF2 are more difficult to treat than those of sporadic unilateral VS because NF2-related VS are often multifocal in the eighth nerve complex, and the potential for associated facial nerve schwannomas. Surgery to remove VS in NF2 almost always leads to total deafness with loss of the cochlear nerve. Despite the great improvement in VS surgery over the last three decades, facial nerve damage and other adverse outcomes remain a real possibility during tumour removal, especially in the hands of less experienced VS surgeons. Facial weakness may threaten the health of the eye as a result of loss of the protective blink reflex. and as the lacrimal gland is also supplied by the facial nerve the loss of tear production will increase this risk. If facial nerve damage coexists with loss of corneal sensation from damage to the trigeminal nerve then the eye becomes exceptionally vulnerable to corneal ulceration and blindness.

The cornerstone of modern NF2 management is conservation of function, and the maintenance of "quality of life". The mere presence of a tumour is not an indication for its removal. Serious thought must be given to the benefits 
that are sought and the risks and complications of the surgery, and the treatment must be tailored to the needs of the individual patient [52]. Attempts at hearing preservation surgery should be limited to experienced centres who can offer a realistic chance of maintaining both the cochlear nerve, but also cochlea function. If hearing is lost after apparent cochlear nerve preservation the patient may still be suitable for a cochlear implant. In many if not most instances the best policy will be to observe VS to decide on the best time to balance surgical morbidity against the almost inevitable loss of hearing.

The principle of minimal interference for VS applies equally to schwannomas on other cranial nerves, to intracranial meningiomas, and to spinal tumours. It is very uncommon to have to remove a schwannoma growing on a cranial nerve other than the eighth because these tumours appear to have a much slower growth pattern than NF2 VS. Spinal tumours are mostly considered for excision if they are clearly producing symptoms or physical signs. In the absence of any dramatic growth of tumours, the head should be scanned every year and the spine every 3 years.

\section{Radiation therapy}

It is important to balance the use of microsurgery and radiation treatment, which has a role in patients who are poor surgical candidates, or who refuse or wish to avoid surgery because of its associated risks. Radiation therapy should be mentioned as a management option, even if the tumour is larger than the size criterion for treatment. The upper limit of size for radiotherapy is generally a maximum intracranial diameter of $3 \mathrm{~cm}$ [55]. The patient should be aware of the management options even if the tumour is not suitable for a particular treatment modality. In NF2 cases selected for radiosurgery tumour control rates are of the order of $50 \%$, with $40 \%$ retaining pre-treatment hearing for at least 3 years [56]. This is nonetheless substantially worse than for sporadic vestibular schwannomas.

Surgeons should use clinical judgement as to when to recommend radiation therapy [52]. Follow-up for life with interval scanning is necessary, although this would be required for NF2 anyway. Patients should be made aware of the variable reported outcomes of the treatment and the risk of the radiation-induced malignant change, which has been reported disproportionately more in NF2 than sporadic patients $[57,58]$. The tumour may also be more difficult to excise after radiotherapy, and that reported facial nerve outcomes after surgery following stereotactic radiation therapy are frequently poor [59].

\section{New therapies}

The NF2 protein appears to impact on multiple intracellular signalling pathways. These pathways include the PI3-
kinase/Akt, Raf/MEK/ERK and mTOR pathways [60]. In particular, studies using NF2-derived tumour tissue reveal elevated levels of phosphorylated Akt. More recently, Aktdependent phosphorylation of Merlin on 2 residues (Thr230 and Ser-315) has been shown to target Merlin for ubiquitin-dependent degradation. Although no PI3 kinase or Akt inhibitors have yet been approved for treatment, there are multiple compounds in development primarily for oncology indications. The Raf/MEK/ERK pathway has been implicated in NF2 tumorigenesis in part through identification of elevated levels of phosphoERK and phospho-MEK.

The progress being made in cellular research especially with regard to pathways in which the NF2 gene product interacts raises the hopes of targeted therapy. Targeting the ERK1/, AKT, integrin/focal adhesion kinase/Src/Ras signaling cascades, PDGFRbeta, phosphatidylinositol 3kinase/protein kinase C/Src/c-Raf pathway, VEG-F and other pathways $[60,61]$ means that drugs such as avastin, elotinib [62], lapatinib and sorafenib [63] may well bear fruit.

\section{Prognosis}

NF2 remains a life limiting and life spoiling condition. Patients diagnosed prior to 1990 had only a 15 year life expectancy from diagnosis $[1,64]$. Improvement in management and early diagnosis are improving these outcomes but many people with NF2 still die very young. Prognosis is adversely affected by early age at onset, number of meningiomas and having a truncating mutation [52].

\section{Unresolved questions}

1. What is the most appropriate molecular/cell biological target(s) for therapy

2. What are the long term safety issues of radiation treatments and does fractionated radiotherapy offer advantages over sterotactic or gamma knife treatment

\section{Conclusion}

NF2 remains a condition that is life spoiling and life limiting. Multidisciplinary management with early diagnosis are mainstays of management. Hopefully new targeted therapies will revolutionise the outcomes in this condition.

\section{Abbreviations}

NF2: neurofibromatosis type 2; MRI: magnetic resonance imaging; NF1: neurofibromatosis type 1; VS: vestibular schwannomas; CNS: central nervous system; NIH: National Institutes of Health; SSCP: single strand conformational polymorphism; MLPA: multiplex ligationdependant probe amplification; LOH: loss of constitutional heterozygosity. 


\section{Competing interests}

The author declares that they have no competing interests.

\section{References}

I. Evans DGR, Huson S, Donnai D, Neary W, Blair V, Newton V, Harris $\mathrm{R}$ : A clinical study of type 2 neurofibromatosis. Q J Med 1992 , 84:603-6I8.

2. Rouleau GA, Merel P, Lutchman M, Sanson M, Zucman J, Marineau C, Hoang-xuan K, Demczuk S, Desmaze C, Plougastel B, Pulst SM, Lenoir G, Bijlsma E, Fashold R, Dumanski J, de Jong P, Parry D, Eldridge R, Aurias $A$, Delattre $O$, Thomas $G$ : Alteration in a new gene encoding a putative membrane-organizing protein causes neuro-fibromatosis type 2. Nature 1993, 363:5 I5-52I.

3. Troffater JA, MacCollin MM, Rutter JL, Murrell JR, Duyao MP, Eldridge R, Kley N, Menon AG, Pulaski K, Haase VH, Ambrose CM, Munroe D, Bove C, Haines JL, Martuza RL, MacDonald ME, Seizinger BR, Short PM, Buckler AJ, Gusella JF: A novel moesin-, ezrin-, radixin-like gene is a candidate for the neurofibromatosis $\mathbf{2}$ tumor suppressor. Cell 1993, 72:791-800.

4. Evans DGR, Wallace A, Trueman L, Strachan T: Mosaicism in classical neurofibromatosis type 2: a common mechanism for sporadic disease in tumor prone syndromes? Am J Hum Genet 1998, 63:727-736.

5. Evans DGR, Huson SM, Donnai D, Neary W, Blair V, Teare D, Ramsden RT, Harris R: A genetic study of type $\mathbf{2}$ neurofibromatosis in the north west of England and the UK: I. Prevalence, mutation rate, fitness and confirmation of maternal transmission effect on severity. J Med Genet 1992, 29:84I-846.

6. Evans DGR, Moran A, King A, Saeed S, Gurusinghe N, Ramsden R: Incidence of Vestibular Schwannoma and Neurofibromatosis 2 in the North West of England over a 10 year period: higher incidence than previously thought. Otol Neurotol 2005, 26(I):93-97.

7. Antinheimo J, Sankila R, Carpén $O$, Pukkala E, Sainio $M$, Jääskeläinen J: Population-based analysis of sporadic and type 2 neurofibromatosis-associated meningiomas and schwannomas. Neurology 2000, 54(I):71-76.

8. Wishart $\mathrm{JH}$ : Case of tumours in the skull, dura mater, and brain. Edinburgh Med Surg J 1822, I 8:393-397.

9. Cushing $\mathrm{H}$ : Tumors of the nervus acusticus and the syndrome of the cerebello-pontine angle. WB Saunders, Philadelphia, USA 1917

10. Crowe FW, Schull WJ, Neal JV: A clinical pathological and genetic study of multiple neurofibromatosis. Springfield, Illinois, USA: Charles C. Thomas; 1956.

II. Kanter WR, Eldridge R, Fabricant R, Allen JC, Koerber T: Central neurofibromatosis with bilateral acoustic neuroma. Genetic clinical and biochemical distinctions from peripheral neurofibromatosis. Neurol 1980, 30:851-859.

12. Parry DM, Eldridge R, Kaiser-Kupfer MI, Bouzas EA, Pikus A, Patronas N: Neurofibromatosis 2 (NF2): Clinical characteristics of 63 affected individuals and clinical evidence for heterogeneity. Am J Med Genet 1994, 52:450-45।.

13. Mautner VF, Lindenau M, Baser ME, Hazim W, Tatagiba M, Haase W, Samii M, Wais R, Pulst SM: The neuroimaging and clinical spectrum of neurofibromatosis 2. Neurosurg 1996, 38:880-885.

14. Evans DGR, Ramsden R, Birch J: Paediatric presentation of type 2 neurofibromatosis. Arch Dis Child 1999, 81:496-499.

15. Sperfeld AD, Hein C, Schroder JM, Ludolph AC, Hanemann CO Occurrence and characterization of peripheral nerve involvement in neurofibromatosis type 2. Brain 2002, 1 25:996-1004

16. Seizinger BR, Rouleau GA, Ozelius LG, Ozelius LJ, Faryniarz AG, lannazzi J, Hobbs W, Roy JC, Falcone B, Huson S: Genetic linkage of von Recklinghausen neurofibromatosis to the nerve growth factor receptor gene. Cell 1987, 49:589-594.

17. Rouleau G, Seizinger BR, Ozelius LG, Hobbs WJ, Trofatter JA, Seizinger BR, Martuza RL, Superneau DW, Conneally PM, Gusella JF: Genetic linkage analysis of bilateral acoustic neurofibromatosis to a DNA marker on chromosome 22. Nature 1987, 329:246-248.

18. National Institutes of Health Consensus Development Conference Statement on Neurofibromatosis: Arch Neurol. I 987, 45(5):575-578.
19. Seizinger BR, Martuza RL, Gusella JF: Loss of genes on chromosome 22 in tumorigenesis of human acoustic neuroma. Nature 1986, 322:644-647.

20. MacCollin M, Ramesh V, Jacoby LB, Louis DN, Rubio MP, Pulaski K, Trofatter JA, Short MP, Bove C, Eldridge R: Mutationalanalysis of patients with neurofibromatosis 2. Am J Hum Genet 1994, 55:314-320.

21. Parry DM, MacCollin M, Kaiser-Kupfer MI, Pulaski K, Nicholson HS, Boleseta M, Eldridge R, Gusella JF: Germ-line mutations in the neurofibromatosis 2 gene: correlations with disease severity and retinal abnormalities. Am J Hum Genet 1996, 59:529-539.

22. Ruttledge $\mathrm{MH}$, Andermann AA, Phelan CM, Claudio JO, Han F-y, Chretien N, Rangaratnam S, MacCollin M, Short P, Parry D, Michels V, Riccardi VM, Weksberg R, Kitamura K, Bradburn JM, Hall BD, Propping P, Rouleau GA: Type of mutation in the neurofibromatosis type 2 gene (NF2) frequently determines severity of disease. Am J Hum Genet 1996, 59:33 I-342.

23. Kluwe L, Bayer S, Baser ME, Hazim W, Haase W, Funsterer C, Mautner VF: Identification of NF2 germ-line mutations and comparison with neurofibromatosis 2 phenotypes. [published erratum in Hum Genet 1997;99(2):292]. Hum Genet 1996, 98:534-538.

24. Kluwe L, MacCollin M, Tatagiba M, Thomas S, Hazim W, Haase W Mautner VF: Phenotypic variability associated with 14 splicesite mutations in the NF2 gene. Am J Med Genet I998, 77:228-233.

25. Evans DGR, Trueman L, Wallace A, Mason S, Strachan T: Genotype/ phenotype correlations in type 2 neurofibromatosis: evidence for more severe disease with truncating mutations. J Med Genet 1998, 35:450-455.

26. Baser ME, Kuramoto L, Joe H, Kuramoto L, Joe H, Friedman JM, Wallace AJ, Ramsden RT, Evans DG: Genotype-Phenotype Correlations for Nervous System Tumors in Neurofibromatosis 2: A Population-Based Study. Am J Hum Genet 2004, 75:23 I-239.

27. Baser ME, Kuramoto L, Woods RH, Friedman JM, Wallace AJ, Ramsden RT, Olschwang S, Bijlsma E, Kalamarides M, Papi L, Kato L, Evans DG: The location of constitutional neurofibromatosis 2 (NF2) splice-site mutations is associated with the severity of NF2. J Med Genet 2005, 42(7):540-6.

28. Tsilchorozidou T, Menko F, Lalloo F, Kidd A, Da Silva R, Smith P, Malcolmson A, Dore J, Madan K, Brown A, Yovos JG, Tsaligopoulos M, Vogiatzis N, Wallace A, Evans DGR: Constitutional rearrangements of chromosome 22 as a cause of neurofibromatosis type 2. J Med Genet 2004, 4 I (7):529-534.

29. Kluwe L, Nygren AO, Errami A, Heinrich B, Matthies C, Tatagiba M, Mautner V: Screening for large mutations of the NF2 gene. Genes Chromosomes Cancer 2005, 42(4):384-391.

30. Baser ME: Neurofibromatosis 2 (NF2) mutation databases. [http://www.hgmd.cf.ac.uk/nf2/].

31. Baser ME, the contributors to the International NF2 Database Mutation: The distribution of constitutional and somatic mutations in the neurofibromatosis 2 gene. Hum Mutat. 2006, 27(4):297-306.

32. Ahronowitz I, Xin W, Kiely R, Sims K, Maccollin M, Nunes FP: Mutational spectrum of the NF2 gene: a meta-analysis of 12 years of research and diagnostic laboratory findings. Hum Mutat 2007, 28(I): I- I2

33. Kluwe L, Mautner VF, Heinrich B, Dezube R, Jacoby LB, Friedrich RE, MacCollin $\mathrm{M}$ : Molecular study of frequency of mosaicism in neurofibromatosis 2 patients with bilateral vestibular schwannomas. J Med Genet 2003, 40:109-I14

34. Moyhuddin A, Baser ME, Watson C, Purcell S, Ramsden RT, Heiberg A, Wallace AJ, Evans DGR: Somatic mosaicism in neurofibromatosis 2:prevalence and risk of disease transmission to offspring. J Med Genet 2003, 40:459-463.

35. Evans DG, Ramsden RT, Shenton A, Gokhale C, Bowers NL, Huson SM, Wallace A: Mosaicism in NF2 an update of risk based on uni/bilaterality of vestibular schwannoma at presentation and sensitive mutation analysis including MLPA. J Med Genet 2007, 44(7):424-428.

36. Evans DGR, Maher ER, Baser ME: Age-related shift in the mutation spectra of germline and somatic NF2 mutations: hypothetical role of DNA repair mechanisms. J Med Genet 2005, 42(8):630-632

37. Warren C, James LA, Varley JM, Ramsden RT, Evans DG: Identifying Recurrent Regions of Chromosome Loss and Gain in 76 Ves- 
tibular Schwannomas Using Comparative Genomic Hybridisation (CGH). J Med Genet 2003, 40(I I):802-806.

38. Kino T, Takeshima H, Nakao M, Nishi T, Yamamoto K, Kimura T, Saito Y, Kochi M, Kuratsu J-i, Saya H, Ushio Y: Identification of the cis-acting region in the NF2 gene promoter as a potential target for mutation and methylation-dependent silencing in schwannoma. Genes Cells 200I, 6:44I-454.

39. Gonzalez-Gomez P, Bello MJ, Alonso ME, Lomas J, Lopez-Marin I, Arjona D, de Campos JM, Vaquero J, Isla A, Lassaletta L, Gutierrez M, Sarasa JL, Rey JA: CpG island methylation in sporadic and neurofibromatosis type 2-associated schwannomas. Clin Cancer Res 2003, 9:5601-5606.

40. Lomas J, Bello MJ, Arjona D, Alonso ME, Martinez-Glez V, LopezMarin I, Aminoso C, de Campos JM, Isla A, Vaquero J, Rey JA: Genetic and epigenetic alteration of the NF2 gene in sporadic meningiomas. Genes Chrom Cancer 2005, 42:3।4-319.

4I. Evans DGR, Ramsden RT, Shenton A, Gokhale C, Bowers NL, Huson SM, Wallace $A$ : What are the implications in individuals with unilateral vestibular schwannoma and other neurogenic tumors? J Neurosurg 2008, 108(I):92-96.

42. Evans DGR, Ramsden RT, Shenton A, Gokhale C, Bowers NL, Huson SM, Wallace A: Should NF2 mutation screening be undertaken in patients with an apparently isolated vestibular schwannoma? Clin Genet 2007, 7 I(4):354-358.

43. Baser ME, Friedman JM, Wallace AJ, Ramsden RT, Joe H, Evans DG: Evaluation of diagnostic criteria for neurofibromatosis 2. Neurology 2002, 59(II): 1759-1765.

44. Evans DGR, Newton V, Neary W, Baser ME, Wallace A, MacLeod R, Jenkins JPR, Gillespie J, Ramsden R: Use of MRI and audiological tests in pre-symptomatic diagnosis of type 2 neurofibromatosis (NF2). I Med Genet 2000, 37:944-947.

45. Mohyuddin A, Neary WJ, Wallace AJ, Purcell S, Wu C-L, Reid H, Ramsden RT, Read AP, Evans DGR: Molecular genetic exclusion of NF2 in young patients diagnosed with a unilateral vestibular schwannoma. J Med Genet 2002, 39:3I5-322.

46. Kluwe L, Freidrich RE, Tatagiba M, Mautner V: Presymptomatic diagnosis for children of sporadic neurofibromatosis 2 patients, a method based on tumor analysis. Genet Med 2002, 4:27-30.

47. Mautner VF, Lindenau M, Baser ME, Tatagiba M, Haase W, Samii M, Wais R, Pulst SM: The neuroimaging and clinical spectrum of neurofibromatosis 2. Neurosurg 1996, 38:880-885.

48. King A, Biggs N, Ramsden RT, Wallace A, Gillespie J, Evans DGR: Spinal tumors in neurofibromatosis type 2: is emerging knowledge of genotype predictive of natural history? J Neurosurg Spine 2005, 2(5):574-579.

49. Patronas NJ, Courcoutsakis N, Bromley CM, Katzman GL, MacCollin M, Parry DM: Intramedullary and spinal canal tumors in patients with neurofibromatosis 2: MR imaging findings and correlation with genotype. Radiology 200I, 2 1 8(2):434-442.

50. Evans DGR, Ramsden R, Huson SM, Harris R, Lye R, King TT: Type 2 neurofibromatosis: the need for supraregional care? J Laryngol Otol 1993, 107:40|-406.

5I. Slattery WH, Brackmann DE, Hitselberger W: Hearing preservation in neurofibromatosis type 2. Am J Otol 1998, 19:638-643.

52. Evans DGR, Baser ME, O'Reilly B, Rowe J, Gleeson M, Saeed S, King A, Huson S, Kerr R, Thomas N, Irving R, MacFarlane R, Ferner R, McLeod R, Moffat D, Ramsden R: Management of the patient and family with Neurofibromatosis 2: A consensus conference statement. Brit J Neurosurg 2005, 19:5-12.

53. Baser ME, Friedman JM, Aeschilman D, Joe H, Wallace AJ, Ramsden RT, Evans DGR: Predictors of the risk of mortality in neurofibromatosis 2. Am J Hum Genet 2002, 71:715-723.

54. Sobel RA, Wang Y: Vestibular (acoustic) schwannomas: histological features in neurofibromatosis 2 and in unilateral cases. J Neuropathol Exp Neurol 1993, 52: 106-II3.

55. Rowe JG, Radatz M, Walton L, Kemeny AA: Stereotactic radiosurgery for type $\mathbf{2}$ neurofibromatosis acoustic neuromas: patient selection and tumour size. Stereotact Funct Neurosurg 2002, 79:107-116.

56. Rowe JG, Radatz MW, Walton L, Soanes T, Rodgers J, Kemeny AA: Clinical experience with gamma knife stereotactic radiosurgery in the management of vestibular schwannomas secondary to type 2 neurofibromatosis. I Neurol Neurosurg Psychiatry 2003, 74(9): | 288-1293.
57. Baser ME, Evans DGR, Jackler RK, Sujansky E, Rubenstein A: Malignant peripheral nerve sheath tumors, radiotherapy, and neurofibromatosis 2. Brit J Cancer 2000, 82:998.

58. Evans DGR, Birch JM, Ramsden RT, Sharif S, Baser ME: Malignant transformation and new primary tumours after therapeutic radiation for benign disease: substantial risks in certain tumour-prone syndromes. J Med Genet 2006, 43(4):289-94.

59. Friedmann RA, Slattery WH, Brackmann DE, Shwartz MS, Hitselberger WE: Resection of Acoustic Neuroma following Failed Stereotactic Radiosurgical Treatment: Facial nerve outcome. In Fourth International Conference on Vestibular Schwannoma and Other CPA Lesions. Conference Proceedings Edited by: Baguley DM, Ramsden RT, Moffat DA. Pubs: Immediate Proceedings, Bungay, Norfolk, UK:29-30.

60. Evans DG, Kalamarides M, Hunter-Schaedle $K$, et al: Consensus Recommendations to Accelerate Clinical Trials for Neurofibromatosis Type 2. Clin Cancer Res 2009 in press.

61. Hanemann CO: Magic but treatable? Tumours due to loss of merlin. Brain 2008, I 3 I (Pt 3):606-6I5.

62. Plotkin SR, Singh MA, O'Donnell CC, Harris G], McClatchey AI, Halpin C: Audiologic and radiographic response of NF2related vestibular schwannoma to erlotinib therapy. Nat Clin Pract Oncol 2008, 5(8):487-491.

63. Ammoun S, Flaiz C, Ristic N, Schuldt J, Hanemann CO: Dissecting and targeting the growth factor-dependent and growth factor-independent extracellular signal-regulated kinase pathway in human schwannoma. Cancer Res 2008, 68( I3):5236-5245.

64. Evans DGR, Huson SM, Donnai D, Neary W, Blair V, Newton V, Strachan T, Harris R: A genetic study of type 2 neurofibromatosis: II Guidelines for genetic counselling. J Med Genet. 1992, 29( I 2):846-852.

Publish with Bio Med Central and every scientist can read your work free of charge

"BioMed Central will be the most significant development for disseminating the results of biomedical research in our lifetime. "

Sir Paul Nurse, Cancer Research UK

Your research papers will be:

- available free of charge to the entire biomedical community

- peer reviewed and published immediately upon acceptance

- cited in PubMed and archived on PubMed Central

- yours - you keep the copyright 